\section{Using 'science laboratory interaction category' instrument to assess laboratory behavior of grade-8th basic science students' in Nigeria}

Atomatofa, Rachel O.

Delta State College of Physical Education, Mosogar, Nigeria (atomatofa.ro@gmail.com)

Ajaja, Patrick O.

Delta State University Abraka, Nigeria (ajajapatrick@yahoo.com)

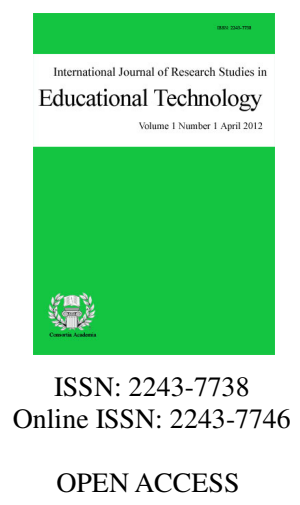

Accepted: 23 June 2017

\title{
Abstract
}

School Laboratory Environments are considered very important for learning to take place effectively. Using the Science Laboratory Interaction Category (SLIC) as instrument, this study assessed the behavior of high and low ability learners in two laboratory environments; the constructivist laboratory environment which served as experimental group and the transmissive laboratory environment which served as control group. 96 grade-8th students formed the study sample. This study employed the pre-test; post-test quasi-experimental design. The design is a $2 \times 2 \times 2$ factorial design consisting of two laboratory environments (constructivist and transmissive); ability at two levels (high and low); and repeated testing (pre-test and post-test). The research instruments used to obtain data for which two research questions and one hypothesis was tested are the Science Laboratory Interaction Category (SLIC) and Basic Science Achievement Test (BSACT). The teaching content used was the same for both groups. Results show that the behaviors of both the 'high and low' constructivist students were more favorable than behavior of 'high and low' transmissive students in exhibition of acceptable laboratory behavior. Also, there was no significant difference in the exhibition of acceptable laboratory behavior between 'high and low' ability constructivist groups; but significant differences were found between the 'high and low' transmissive groups. Based on the results, recommendations were made to train teachers to assess laboratory behaviors using the SLIC instrument and encouraging teachers to create laboratory environment that foster better laboratory behavior.

Keywords: science laboratory; laboratory environment; behavior; ability levels 


\section{Using 'science laboratory interaction category' instrument to assess laboratory behavior of grade-8th basic science students' in Nigeria}

\section{Introduction}

Children are not retarded but their behavior can be retarded in an average environment (Lindsley, 1964). It is the duty of teachers to create suitable learning environments for learners to facilitate behavior. Learners have been found to improve in their behavior, gain confidence and embark on more complex tasks set by their teachers during science laboratory activities, depending on the kind of laboratory environment their teacher creates. A good teacher is responsible for creating the laboratory environment that will facilitate learners' acquisition of knowledge. He designs his practical sessions so that students' understanding are improved and there are positive interactions amongst students during laboratory sessions.

Science laboratories are places where scientists work. Laboratory exercises are integral parts of science teaching. And a laboratory is used when a practical is to be carried out in order to obtain or verify information. The science laboratory environment should be pleasant and conducive for effective learning and effective behavior on the part of the students. According to Lindsley (1964), teachers are to assume that students respond in different environment, therefore if students are not behaving well, it is the duty of teachers to recreate a more suitable environment that will bring out best behavior in students. This means that if Lindsey is correct, the behavior of students in the constructivist environment will be different from the behavior of students in the transmissive environment.

Literatures show that few researches have been carried out to help teachers access and improve their laboratory learning environment in integrated science subject now Basic Science in Nigeria (Igwebuike, 2000, 2012; Ajaja, 1998; Aiyedun, 2000; and Nwagbo \& Obiekwe, 2010). Research also show that the Science Laboratory Interaction Category instrument which assesses students' laboratory behavior has not been used by Basic science teachers in Nigeria, to assess students' laboratory behaviors in a constructivist and transmissive laboratory where behaviors are different (Atomatofa, 2014) The Science Laboratory Interaction Category (SLIC) used in this study is an instrument used to record and analyze students' laboratory behavior during practical sessions in the laboratory. It uses categories of behavior which includes asking questions, reading lesson-related materials and moving around the laboratory.

This study emphasizes the role of teachers as those that create the laboratory environments for the students to learn and that the laboratory environment can affect students' achievement as well as their behavior. It examined whether there are significant differences in laboratory behavior among grade-8th students taught basic science in two teacher-created learning environments- the constructivist laboratory environment and the transmissive laboratory environments. It also considered if ability levels affect laboratory behavior and academic performance in the different laboratories.

\section{Literature review}

\subsection{Theoretical framework}

This study is founded on Constructivism which is an epistemology of learning that emphasizes learning occurring as a result of actively involving students in construction of their own meanings. It maintains that if students are taught in an environment and in ways that help them construct their own knowledge under close supervision by the teacher, students will become more interested and more involved in learning science. Constructivism according to Haman and Embi (2010), is a philosophy that at its most basic levels, views 
knowledge as constructed internally by a person as opposed to the objectivists view which views reality as being fixed and external and it is a branch of philosophy which tries to understand how learners construct knowledge. Constructivism is said to be excellent in providing a valuable framework for teaching in a science laboratory learning environments (Hussian, Igbal, \& Akhtar, 2011).

The primary contributors of constructivism, according to Atomatofa (2014), include: John Dewey (1859-1952); Maria Montessori (1870-1952); Wladyslaw Strezeminski (1893-1952); Jean Piaget (1896-1980); Lev Vygotsky (1896-1934) amongst others. These authors have contributed to the three branches of constructivism which are cognitive constructivism, radical constructivism, and social constructivism. Cognitive constructivists emphasize mental constructions of reality. Radical constructivists emphasize the construction of a coherent experiential reality while Social constructivists emphasize the construction of an agreed-upon or socially constructed reality.

Lev Vygotsky was the major proponent of social constructivism. Social constructivism emphasizes social interaction as a basis for knowledge construction that provides for the development of socially relevant skills and knowledge. The Lev Vygotsky's theory of social constructivism which this research is tied to, states that "all cognitive function begins as a product of social interactions and that knowledge is not just assimilated but a collaborative process" Vygotsky (1978). Social constructivism is essentially a theory about how people socially construct knowledge. Vygotsky theory is unique, because it explains that learning cannot be separated from social context. In the laboratory, both the teacher and students are expected to collaborate and carry out the practicals together. Hence the Science Laboratory Interaction Category instrument was carefully chosen for assessing the behavior of the students in the lab. It assesses (these) 10 categories of behaviors which students are likely to exhibit during laboratory exercises (SETQLORWMZ - show; manipulating apparatus; transmits information; ask questions; listen; observe; reads lesson-related material; writes notes or records data; moves around the room to gets supplies; and non-lesson- related behavior).

An observation of the behavior of students during practical sessions in different laboratory environments will tell the laboratory environment that best stimulates students to achieve better as well as behave better. In this study, the researcher compared the laboratory behavior of students in two laboratory environment using the Science Laboratory Interaction Category instrument to assess their behavior. The behavior of students in the high and low ability levels will also be compared.

\subsection{Review of related literature}

Kardash and Wallace (2001) found out that students interest and perception of their learning environment can decrease or increase depending on how the teacher creates the laboratory learning environment. They gave this as one reason why students switch over from science to non-sciences or even fail sciences when they remain. By early adolescence, some students begin to purposely withdraw efforts, resist novel approaches to learning and avoid seeking academic help when they need it. These attitudes often relate to low performance and contribute to poor performance of students (Turner, Midgley, Gheen, Anderman, Kang, \& Patrick, 2002). This is what makes the position of a constructivist teacher to help students get involved in their learning. They stimulate them and provoke critical thinking skills; they create authentic and problem solving activities in the classroom. This attitude prevents boredom, withdrawal and poor performances. Hussain, Igbal and Akhtal (2010) found that the students taught in the constructivist environment did better than those taught in the conventional classrooms. They also found that there was a strong correlation between academic achievement and classroom learning environment.

A lot of researches have been carried out that compares constructivist students' performance with students performances in several classroom learning environments, but few researches have been carried out that compares students' behavior and performance in the laboratory. The laboratory environment created by the teacher during practical session also relates to the teacher's teaching approach; be it constructivist or 
transmissive. The teacher's presentation according to Keller (2007), Nwagbo (2001) and Nwagbo (2011) in separate studies are essential for good behavior. When a student is in charge of an activity it reduces wrong behavior. According to them, "the teacher-created environment should be friendly, matured and controlled and the learning environment should be student-centered". When students are allowed to "handle" and "manipulate" materials, boredom and distractions are reduced and laboratory is enhanced. As McGowen (2007) puts it, the behavior of students is often driven by how they perceive the learning environment, therefore, teachers can manipulate the classroom climate from a constricting to an engaging one and these changes can increase positive behavior.

Several research reports that prove that students do better in the constructivist learning environments, however there are several reasons why most teachers still prefer to create the transmissive environment. Bankefa (1998) discovered that the non-availability of materials for practicals in the science laboratories were among reasons why teachers create the transmissive laboratory environment where social-friendly relationships between teacher and students was minimal. This may also be why some researchers discovered that students taught in a teacher-centered learning environment did better than their counterparts in a learner-centered environment. Igwebuike (2000) found out that there was no significant difference in the cognitive achievement of students taught integrated science in a constructivist environment and in a traditional environment. He however stated that the students in the traditional environment performed as effective as those in the constructivist group.

In addition, Ibeneme (2005) found out that there were no significant differences between achievements of students in the constructivists and conventional classrooms in the achievement test in introductory technology subjects but more emphasis according to them should be placed on the constructivist learning environment since it is new and needs more time for full unfolding of fits potentials. Andrusyszn (2004) discovered in a research carried out in Canada that students taught using lecture -discussion method with audio-visual augmentation did not do better than their counterpart in the non-augmented group. This means students in the non-augmented lecture-discussion group performed equally as those in the augmented group. This shows that the lecture or transmissive strategy when properly used in a well-organized environment can result to students' high students' achievement in science. The reviews above shows that students can have high achievement in science when taught in a transmissive environment provided the teacher is able to present his teaching effectively. As Akinseide (1998), Abdullahi (1982) and Gbamanja (1991) in separate studies puts it, the teacher should speak loud and clear enough to be heard, use humor to hold learner's interest, use appropriate gestures, ask thought provoking questions that will provoke critical thinking.

On ability levels, Turner et al. (2002) found out in their study of classroom learning environment that by early adolescence, some students have begun to purposefully withdraw efforts, resist novel approaches to learning and avoid seeking academic help when they need it. They discovered from their research that this attitude of avoidance in science adolescent students was related to students of low ability groups. This attitude undermines their performance and contributes to poor performances of low ability students. This weakness can be taken care of when teachers create classroom and laboratory climate that is more student centered than teacher centered. The task of teaching science concepts more meaningfully is not often fulfilled in a teacher-centered classroom where information is presented by the teacher while students make use of their auditory and usual information at a later date. One fundamental premise of the constructivist environment is that children actively construct their knowledge rather than absorb it. Some researchers have found out that students' ability levels can be used to predict their cognitive achievement from instruction (Ajaja, 1998; Atomatofa, 2014; Igwebuike, 2000) hence this study found out the effect of "teacher-created" laboratory environment on behavior of high and low ability grade- 8 basic science students' in Nigeria.

In this research, the transmissive and the constructivists' laboratory environments were created by the teachers and the behavior of high and low ability students were compared. 


\subsection{Research questions}

$>\quad$ Will there be Pre-test and Post-test differences in laboratory behavior patterns of high and low ability students in each item of the Science Laboratory Interaction Category instruments in the constructivist and transmissive laboratory environments?

$>\quad$ Will there be differences in the mean laboratory behavior scores of high and low ability students in a constructivist and in a transmissive laboratory in a test of BSACT?

\subsection{Research hypothesis}

$>\quad$ There is no significant difference in the mean laboratory behavior scores of high and low ability students in a constructivist and in a transmissive laboratory in a test of BSACT.

\section{Methods}

This study employed the pre-test; post-test quasi-experimental design. The design is a 2 × 2 × 2 factorial design, consisting of two laboratory environments created by the teachers (constructivists and the transmissive laboratory environments), ability at two levels (high and low) and repeated testing (pre-test \& post-test). The design shows pre-test and post-test of all the subjects in the different groups in behavior rating and achievement test. The design chosen controlled for major threats to internal and external validity such as the ability to measure a phenomenon before and after treatment. A total of 96 students were used (43 high and 53 low ability). Students who were in the middle ability groups after a preliminary test of Basic Science Scholastic Ability test was applied were not used for this study. On instrumentation, the Science Laboratory Interaction Category used in this research assessed the behavior of the students in the two laboratory environments. It was originally constructed by Shymansky, Penick, and Kyle (1977) and has been used by several researchers in science education to gather information on the behavior of science teachers and students during practical sessions in the lab (Ajaja, 1998, 2005, 2006; Okebukola, 1985). It consists of 10 categories of students' behaviour and 15 categories of teachers' behaviour. For student behavior, it uses categories such as: (1) asking questions (2) reading lesson-related materials (3) moving around the lab and so on.

The validity and reliability of the Science Laboratory Interaction Category were done. The inter-rater reliability was used to establish the reliability of the Science Laboratory Interaction Category in this research. According to Landis and Koch (1977), Inter-rater reliability is a measure used to examine the agreement between persons on the assignment of categories of a categorical variable. It is an important measure in determining how well the implementation of some coding or measurement system works. According to Landis and Koch (1977), a statistical measure of inter-rater reliability is Fleiss' kappa which measure of inter-rater reliability is related to Cohen's kappa statistic. Whereas Cohen's kappa works for only two raters, Fleiss' kappa works for any number of raters. It can be interpreted as expressing the extent to which the observed amount of agreement among raters' exceeds what would be expected if all raters' made their ratings completely randomly. Agreement can be thought of as follows, if a fixed number of people assign numerical ratings to a number of items then the kappa will give a measure for how consistent the ratings are. In the pilot study carried out in this study the ratings of 3 observers on 16 students (every 5 seconds for 5 mins per student during a laboratory exercise of $80 \mathrm{mins}$ ) were pooled together and the inter-rater reliability gave a co-efficient of 0.45 which is moderately acceptably according to the table of interpretation below.

\section{Table 1}

Table of interpretation of Fleiss Kappa inter-rater reliability

\begin{tabular}{ccccccc}
\hline & $<0$ & $0.01-0.20$ & $0.21-0.40$ & $0.41-0.60$ & $0.61-0.80$ & $0.80-1.00$ \\
\hline interpretation & $\begin{array}{c}\text { poor } \\
\text { agreement }\end{array}$ & $\begin{array}{c}\text { slight } \\
\text { agreement }\end{array}$ & $\begin{array}{c}\text { fair } \\
\text { agreement }\end{array}$ & $\begin{array}{c}\text { moderate } \\
\text { agreement }\end{array}$ & $\begin{array}{c}\text { substantial } \\
\text { agreement }\end{array}$ & $\begin{array}{c}\text { perfect } \\
\text { agreement }\end{array}$ \\
\hline
\end{tabular}


The Basic Science Achievement Test (BSACT) was another instrument used to test students' knowledge of the topics they were taught during the laboratory exercises. For the reliability of BSACT, a pilot study was carried out on 30 Grade 9th students who have just completed the Grade 8th Basic Science syllabus containing the topics to be used in this research. Grade 8th students were not used because the students have not been taught the topics intended for this research at that the time of this pilot study. Using the Kuder Richerson 21 formula, reliability co-efficient of 0.82 was obtained. The procedure for experimentation followed this sequence. Two weeks before the 4-week laboratory/ treatment exercises, The pre-test and post of BSACT consisting of 40 objective questions; a preliminary behavior rating using the science laboratory interaction category were given to subjects in the entire group by the trained research assistants. The results were collected the same by the 6 trained research assistants and given to the researcher for data analysis.

The treatment sessions consist of four laboratory exercises carried out on each of the groups in this study. The 96 students were rated by 6 trained observers ( 4 per exercise) their ratings were pooled together and used to code the average behavior of students in each group on the 10 categories of the science laboratory interaction category. At the end treatment exercise, the post-test for the BSACT was administered. The constructivist laboratory environment was friendly, co-operating and stimulating. The arrangement was different from the transmissive laboratory environment which was mainly teacher centered. Data collected from BSACT were analyzed using t-test for each pair wise comparison; on the behavior checklist, ratings were done with a scale of 4 as highest, to 1 as lowest, for each student in each of the 10 categories. And the percentage time spent was calculated for each item in the scale for the various groups.

\section{Results}

\subsection{Answer to Research Question 1}

Will there be Pre-test and Post-test differences in laboratory behavior patterns of high and low ability students in each item of the science laboratory interaction category instruments in the constructivist and transmissive laboratory environments?

Table 2

Percentage time spent in Exhibiting laboratory behavior

\begin{tabular}{|c|c|c|c|c|c|c|c|c|}
\hline \multirow{6}{*}{$\begin{array}{l}\text { Pre/Post } \\
\mathrm{S}=\text { Show }\end{array}$} & \multicolumn{8}{|c|}{ Communication-type } \\
\hline & \multicolumn{8}{|c|}{ Percentage of time spent in exhibiting behavior in each item of SLIC } \\
\hline & \multirow{3}{*}{\multicolumn{2}{|c|}{$\begin{array}{l}\text { Constructivist } \\
\text { High ability } \\
\text { pre-test post-test }\end{array}$}} & \multicolumn{6}{|c|}{ Transmissive } \\
\hline & & & \multicolumn{2}{|c|}{ low ability } & \multirow{2}{*}{\multicolumn{2}{|c|}{$\begin{array}{c}\text { High } \\
\text { pre-test } \\
\text { post-test }\end{array}$}} & \multirow{2}{*}{\multicolumn{2}{|c|}{$\begin{array}{c}\text { Low ability } \\
\text { pre-test } \\
\text { post-test }\end{array}$}} \\
\hline & & & pre-te & pst-test & & & & \\
\hline & 7.1 & 8.3 & 12.4 & 6.6 & 10.5 & 12.3 & 9.9 & 10.3 \\
\hline $\mathrm{E}=$ Manipulates apparatus & 8.2 & 15.0 & 9.1 & 13.8 & 9.5 & 7.2 & 8.7 & 8.7 \\
\hline $\mathrm{T}=$ Transmit Information & 10.3 & 12.0 & 10.4 & 10.2 & 10.9 & 10 & 11.4 & 10.7 \\
\hline $\mathrm{Q}=$ Ask questions & 12.6 & 9.9 & 9.8 & 11 & 12.3 & 10.5 & 9.8 & 10.9 \\
\hline $\mathrm{L}=$ Listen & 12.8 & 4.8 & 12.9 & 4.4 & 9.1 & 10.8 & 9.8 & 10.8 \\
\hline $\mathrm{O}=$ Observes teacher & 9.9 & 5.4 & 14 & 4.8 & 9.5 & 11.4 & 10.7 & 10.4 \\
\hline $\mathrm{R}=$ Reads lesson related materials & 7.5 & 14.6 & 7.8 & 14 & 10.5 & 9.0 & 10.3 & 10.1 \\
\hline $\mathrm{W}=\mathrm{Writes}$ notes or record data & 10.9 & 15.3 & 9.1 & 14.2 & 12.6 & 10.8 & 10.8 & 9.9 \\
\hline $\mathrm{M}=$ Gets supplies of materials & 9.5 & 8.4 & 7.5 & 15.2 & 8.4 & 6.9 & 7.2 & 7.2 \\
\hline $\mathrm{Z}=$ Non-lesson related behavior & 11.2 & 6.3 & 7.0 & 5.8 & 7.1 & 11.1 & 11.4 & 11.8 \\
\hline Total in $\%$ & 100 & 100 & 100 & 100 & 100 & 100 & 100 & 100 \\
\hline
\end{tabular}


The results in table 2 shows that there are pre-test posts test differences in laboratory behavior patterns of students in all the groups; there were improvements in times spent in exhibiting acceptable laboratory behaviors in post-test over pre-test in the following items of the science laboratory interaction category.

> In the High constructivist groups improvements in post-test over pretest occurred in: Show, manipulate apparatus, Transmit information and in reading lesson related materials;

$>$ In the low constructivist group, improvement in post-test over pre-test occurred in: Manipulating of apparatus, asking questions, read lesson related materials and in write notes and; in getting supplies of materials.

> In comparing between high and low constructivist group, the highest times spent in exhibiting acceptable laboratory behavior were in this order: high constructivist (15.3\% record data and $15 \%$ manipulating apparatus); Low constructivist group (15.2\% in get supplies and $14.2 \%$ in record data). Their lowest times were spent in this order; high constructivist (4.8\% listen and 5.4\% observe teacher) low constructivist (4.4\% listen and $4.8 \%$ observe teacher). This result agrees with Etuk, Etuk, and Etudor-Eyo (2011), that constructivist students whether high or low ability, spend more time using their hands and sense organs (in activities such as record data, manipulate apparatus) than just observing or listening while their teacher does everything during practical activities.

$>$ In the high transmissive group there were improvements in times spent in exhibiting acceptable laboratory behaviors in post-test over pre-test in: non-lesson related behavior, observes teacher and show.

> In the low transmissive group, there were improvements in times spent in exhibiting acceptable laboratory behaviors in post-test over pre-test in: show, non-lesson related behavior, listen and ask questions.

$>$ In comparing between high and low transmissive group, highest times were in this order: high transmissive (11.4\% Show and $12.3 \%$ Observe teacher) and low transmissive (11.8\% Non-lesson related behavior and $10.8 \%$ Listen); and lowest times for high transmissive group (8.7\% manipulates apparatus and $7.2 \%$ get supplies) and for the low transmissive group (7.2\% manipulate apparatus and 6.9\% get supplies). According to Keller (2007), Urevbu (1990), and Nwagbo (2001) in separate studies, the climate of the laboratory can influence or retard good behavior. In this case the climate of the transmissive environment retarded the laboratory behavior of the students this is because results shows they spent more times in unacceptable behavior and less times in acceptable laboratory behaviors.

\subsection{Answer to Research Question 2}

Will there be differences in the mean laboratory behavior scores of high and low ability students in a constructivist and in a transmissive laboratory in a test of BSACT?

Result from table 3 shows there are differences in the mean laboratory scores of students in all the groups in this order. Constructivist low and transmissive low (6.98); transmissive high and transmissive low (5.12); Constructivist high and transmissive high (3.24); Constructivist high and Constructivist low (1.38). From the results, the high and low constructivist group had the lowest mean difference while the constructivist low and transmissive low had the highest mean difference. This clearly shows that the constructivist group both high and low had better laboratory scores in a test of BSACT while the transmissive high and low students had the least behavior scores in the BSACT test. Analysis of the research hypothesis will tell if the mean differences are significant or not. 
Atomatofa, R. O., \& Ajaja, P. O.

Table 3

Mean scores of students of high and low abilities in the constructivist and transmissive groups

\begin{tabular}{llcccc}
\hline \multicolumn{1}{c}{ Learning Environment } & Ability group & $\mathrm{N}$ & Means & SD & Mean diff \\
\hline Constructivist & High & 29 & 62.7 & 1.73 & 1.38 \\
Constructivist & Low & 19 & 61.32 & 1.95 & \\
Transmissive & High & 14 & 59.46 & 3.62 & 5.12 \\
Transmissive & Low & 34 & 54.34 & 2.69 & \\
Constructivist & High & 29 & 62.7 & 1.73 & \multirow{2}{*}{3.24} \\
Transmissive & High & 14 & 59.46 & 3.62 & \\
Constructivist & Low & 19 & 61.32 & 1.95 & \multirow{2}{*}{6.98} \\
Transmissive & Low & 34 & 54.34 & 2.69 & \\
\hline
\end{tabular}

\subsection{Test of research hypothesis}

There is no significant difference in the mean laboratory behavior scores of high and low ability students in a constructivist and in a transmissive laboratory in a test of BSACT.

\section{Table 4}

T-tests of the laboratory behavior scores in the constructivist and transmissive groups

\begin{tabular}{lllllllll}
\hline Learning environment & Ability group & $N$ & Mean & $S D$ & $d f$ & $t$-cal & $t$-cri & remark \\
\hline Constructivist & High & 29 & 62.70 & 1.73 & 46 & 2.51 & 2.02 & $\mathrm{~S}$ \\
Constructivist & Low & 19 & 61.32 & 1.95 & & & & \\
Transmissive & High & 14 & 59.46 & 3.62 & 46 & 4.77 & 2.02 & $\mathrm{~S}$ \\
Transmissive & Low & 34 & 54.34 & 2.69 & & & & \\
Constructivist & High & 29 & 62.70 & 1.73 & 41 & 5.78 & 2.02 & $\mathrm{~S}$ \\
Transmissive & High & 14 & 59.46 & 3.62 & & & & \\
Constructivist & Low & 19 & 61.32 & 1.95 & 51 & 6.54 & 2.02 & $\mathrm{~S}$ \\
Transmissive & Low & 34 & 54.34 & 2.69 & & & & \\
\hline
\end{tabular}

Table 4 shows a significant difference in the laboratory behaviour scores occurring in all the groups as summarized below:

$>$ A significant difference between the high and low ability students of the constructivist group on laboratory behavior (the $\mathrm{t}$-calculated value, $\mathrm{t}=2.51$ is higher than the $\mathrm{t}$-critical value of $\mathrm{t}=2.02$ ).

$>\quad$ A significant difference between high and low ability students of the transmissive group on laboratory behavior (the $\mathrm{t}$-calculated value, $\mathrm{t}=4.77$ is higher than the $\mathrm{t}$-critical value of $\mathrm{t}=2.02$ ).

$>$ A significant difference between high constructivist and high transmissive groups (the t-calculated value, $\mathrm{t}=5.78$ is higher than the $\mathrm{t}$-critical value of $\mathrm{t}=2.02$ ).

$>$ A significant difference between students in low constructivist and low transmissive groups (The $\mathrm{t}$-calculated value, $\mathrm{t}=6.54$ is higher than the $\mathrm{t}$-critical value of $\mathrm{t}=2.02$ ).

The highest significant difference was found between the low constructivist and low transmissive group in the exhibition of acceptable laboratory behaviours. Based on these summaries, the hypothesis was rejected.

\section{Conclusion}

In this study the laboratory behaviors of 96 grade-8th basic science students in 2 different laboratory 
Using 'science laboratory interaction category' instrument to assess laboratory behavior of students' in Nigeria

environments (the constructivist and transmissive labs) were observed and their mean laboratory behavior scores were also compared and tested for significant difference. Using the science laboratory interaction category Instrument to assess behavior, results showed that the constructivist laboratory environment best stimulate both the high and low ability grade 8th students to exhibit better laboratory behaviors.

\subsection{Recommendation}

The following recommendations are made based on the results of this study:

$>\quad$ Teachers should be taught during workshops and academic seminars on how to assess the laboratory behavior of students using the science laboratory interaction category instrument.

$>$ Teachers should be encouraged to create environments such as the constructivist environment, because it gives room for learners to partake in their own learning while the teacher guides them; it also brings out the best in students academically and in exhibition of acceptable laboratory behavior.

$>\quad$ Also teachers should take cognizance of ability levels of the students when creating the constructivist learning environment especially during classroom instruction.

\section{References}

Abdullahi, A. (1982). Science teaching in Nigeria. Atoto Press Ltd.

Aiyedun, J. O. (2000). Influence of sex difference of students on their achievement in secondary school mathematics. The Journal of Mathematics Association of Nigeria, 25(1), 102-111.

Ajaja, O. P. (2005). A comparison of the effectiveness of three instructional methods on exhibition of acceptable laboratory behaviour. Journal of Vocational, Science and Educational Development, 6(1, 2), 36-44.

Ajaja, O. P. (2006). A comparison of retention outcome of advance organizer, discovery and invention methods of teaching biology in Nigerian Secondary Schools. The Nigerian Journal of Education, 4(2), 229-240.

Ajaja, O.P. (1998). An evaluation of differential effectiveness of Ausubel, Bruner and Karplus methods of Teaching Biology in Nigerian Secondary Schools (Unpublished Ph.D Thesis). University of Benin.

Akinseide, S. L. (1998). Principles and methods of instruction in technology education. Ibadan. Kenny Ventures

Andrusyszn, M. A. (2004). The effect of the lecture, discussion teaching method with or without audio-visual augmentation on immediate and retention learning. Nurse Education Today, 10, 172-180. https://doi.org/10.1016/0260-6917(90)90022-I

Atomatofa, R. (2014). Effects of constructivists' learning environment on achievements and laboratory behavior of basic science students in Delta State (PHD Thesis). Delta State University Abraka, Nigeria

Bankefa, R. A. (1976). Problems of teaching integrated -science in Oyo state school. Journal of Science Teachers Association of Nigeria, 16(2), 18-21.

Gbamanja, S. P. T. (1991). Modern methods in science education. Owerri: Tosan.

Hamat, A., \& Embi, M. A. (2010). Constructionism in the design of online learning tools. European Journal of Educational Studies, 2(3), 237-246.

Hussian, M. A., Igbal, M. Z., \& Akhtar, S. M. (2010). Technology based learning environment and student achievement in English as a foreign language in Pakistan. World Academy of Science Engineering and Technology, 61, 46-50.

Igboko, K. O., \& Ibeneme, O. T. (2005). Effects of some cognitive constructivism instructional approaches on students' achievement and retention in the study of introductory technology in Nigeria. Journal of Science Teachers Association of Nigeria, 41(1, 2), 37-43.

Igwebuike, T. (2000). The effect of constructivist learning environment on students' achievement in integrated-science (Unpublished Ph.D Thesis). University of Benin. Nigeria

Igwebuike, T. B., \& Oriaifo, S. O. (2012). Nature of classroom environment and achievement in integrated science: A test of efficacy of a constructivist instructional strategy. International Journal of Research 
Atomatofa, R. O., \& Ajaja, P. O.

Studies in Educational Technology, 1(2), 17-29. https://doi.org/10.5861/ijrset.2012.98

Kardash, M., \& Wallace, L. (2001). The perceptions of science classes surveys: What undergraduates science reforms effort really need to address. Journal of educational psychology, 93(1), 199-210. https://doi.org/10.1037/0022-0663.93.1.199

Keller, E. (2007). Strategies for teaching students with behavioral disorders. Retrieved from http://www.as.wvu.edu/scidis/behaviour.html

Landis, J. R., \& Koch, G. (1977). The measurement of observer agreement for categorical data. Biometrics 33, 159-174. https://doi.org/10.2307/2529310

Lindsley, O. R. (1964). Direct measurement and prosthesis of retarded behaviour. Journal of Education, 147, 62-81.

McGowen, R. C. (2007). The impact of school facilities or student achievement, attendance, behaviour, completion rate and teacher turnover rate in selected Texas High Schools (Unpublished $\mathrm{PhD}$ dissertation). Texas University.

Nwagbo, C. R. (2001). The relative efficacy of guided inquiry and expository methods on biological students' achievement of different scientific literacy levels. Journal of Science Teachers Association of Nigeria. 36(1\&2), 43-51.

Nwagbo, C., \& Obiekwe, C. (2010). Effects of constructivist instructional approach on students' achievement on basic ecological concepts in biology. Journal of Science Teachers Association of Nigeria, 45(1\&2) 26-35.

Okebukola, P. A. (1985). Science laboratory behavior strategies of students relative to performance in and attitude to laboratory work. Journal of research in science teaching, 22(3), 221-232. https://doi.org/10.1002/tea.3660220304

Shymansky, J. A., Penick, J., \& Kyle, W. C. (1977). The role of teaching assistants in upper and lower levels laboratory in 5 science disciplines. In O. P. Ajaja (1998), An evaluation of differential effectiveness of Ausubel, Bruner and Karplus methods of teaching biology in Nigerian secondary schools (Unpublished Phd thesis). University of Benin.

Turner, J.C., Midgley C., Gheen, M., Anderman, E., Kang, Y., \& Patrick, H. (2002). The classroom environments and Students reports of avoidance strategies in mathematics. A Multimedia Study. Journal of Educational Psychology, 94(1), 88-106. https://doi.org/10.1037/0022-0663.94.1.88

Vygotsky, L. (1978). Mind in society: The development of higher psychology process. Cambridge, M.A: Harvard University Press (Original work published in 1930). 